\title{
Presser point of chest compression by non-medical personnel
}

\author{
Kouichiro Minami ${ }^{1} \cdot$ Yota Kokubo $^{2}$
}

Received: 17 April 2019 / Accepted: 23 April 2019 / Published online: 22 May 2019

(c) Japanese Society of Anesthesiologists 2019

Keywords Presser point $\cdot$ Chest compression

To the Editor:

In chest compression for cardiopulmonary resuscitation (CPR), the lower half of the sternum is pressed according to the American Heart Association guidelines 2015 [1]. We recently reported that many of the ambulance crews do not press on the sternal lower half definitely in this journal [2]. There has been no report on the pressure point of chest compression with the bystanders who are not medical personnel. Here, we examined the pressure point of chest compression by Non-medical personnel who are supposed to be a bystander during CPR.

Experiment participants included 29 non-medical personnel (male 12, female 17). The experimental procedure was same as described in the paper we previously reported [2]. We tested the chest compression by using our developed device (Shinnosukekun ${ }^{\mathrm{TM}}$, Sumitomo Riko Co., Ltd., Komaki-shi, Aichi, Japan) and reported its efficacy for chest compression quality without and with real time feed back (RTF) by the device (Supplementary Fig. 1). Only 27.6\% $(8 / 29)$ of the experiment participants did not press the centre of the sensor without feedback, but $93.1 \%$ (27/29) pressed

This comment refers to the article available online at https://doi. org/10.1007/s00540-016-2265-3.

Electronic supplementary material The online version of this article (https://doi.org/10.1007/s00540-019-02649-x) contains supplementary material, which is available to authorized users.

Kouichiro Minami

minamitaka311@icloud.com

1 Emergency Life Saving and Technique Tokyo, 4-5

Minamiosawa, Hachioji, Tokyo 192-0364, Japan

2 Health and Nursing Care Products Business Unit, Sumitomo

Riko Company Limited, 3-1 Higashi, Komaki-shi,

Aichi 485-8550, Japan the centre with RTF. The RTF using this devise would be useful not only to improve CPR quality.

Although the guideline recommends that the centre of the chest should be depressed, even if bystanders try to push the middle of the chest it is actually considered difficult to push. Most bystanders would not be able to push on the correct position unless there is RTF equipment. In the CPR education, it would be recommended to use the equipment indicated by the compression position during CPR by bystanders.

Acknowledgements We thank the great help by Toshiki Tamura (Fukoku Bussan Co., Ltd) and Masanori Tuda (Sumitomo Riko Co., Ltd) in this study.

\section{References}

1. Sayre MR, Koster RW, Botha M, Cave DM, Cudnik MT, Handley AJ, Hatanaka T, Hazinski MF, Jacobs I, Monsieurs K, Morley PT, Nolan JP, Travers AH, On behalf of the Adult Basic Life Support Chapter Collaborators. Part 5: adult basic life support: 2010 International Consensus on Cardiopulmonary Resuscitation and Emergency Cardiovascular Care Science with Treatment Recommendations. Circulation. 2010;122(Suppl 2):S298-S324.

2. Minami K, Kokubo Y, Maeda I, Hibino S. Analysis of actual pressure point using the power flexible capacitive sensor during chest compression. J Anesth. 2017;31:152-5.

Publisher's Note Springer Nature remains neutral with regard to jurisdictional claims in published maps and institutional affiliations. 